\title{
Uso da Musicoterapia como Terapia Alternativa no Tratamento da Doença de Parkinson
}

\author{
Fabrina Rodrigues dos Santos $^{1}$, Virgínia Maria Mendes Oliveira Coronago ${ }^{2}$
}

\begin{abstract}
Resumo: A doença de Parkinson é uma doença neurodegenerativa que acomete pessoas idosas principalmente homens, normalmente é tratado com intervenção farmacológica, entretanto os senhores e senhoras não praticam atividades que auxiliam em seu bem-estar, muitas vezes. Desta forma, terapias alternativas estão sendo utilizadas para melhoras a vida em sociedade do paciente, a musicoterapia pode ser uma boa ajuda para a terapia convencional, uma vez que, a música pode ser uma boa alternativa utilizando elementos sonoro-rítmico-musicais. Objetivou-se verificar, a partir de uma revisão sistemática sobre as contribuições desta prática alternativa de tratar melhor esta doença que acomete grande parte da população idosa. Foram utilizados diversos artigos de revisão, de pesquisa ou estudos de caso no intuito de tratar o parkinsonismo usando a musicoterapia atrelada ao tratamento convencional. A partir destes trabalhos utilizados foi percebida a grande melhora na maioria dos casos tanto na qualidade de vida do paciente, quanto das pessoas que o paciente convive, minimizando seu sofrimento.
\end{abstract}

Palavras-chave: Doença de Parkinson; Música; Tratamento alternativo; Idosos

\section{Use of Music Therapy as an Alternative Therapy In the Treatment of Parkinson's Disease}

\begin{abstract}
Parkinson's disease is a neurodegenerative disease that affects mainly elderly people, usually treated with pharmacological intervention, however, ladies and gentlemen do not practice activities that help their wellbeing many times. In this way, alternative therapies are being used to improve the life in the patient's society, music therapy can be a good aid to conventional therapy, since music can be a good alternative using soundrhythmic-musical elements. The objective of this study was to verify, based on a systematic review about the contributions of this alternative practice to better treat this disease that affects a large part of the elderly population. Several articles of review, research or case studies were used in order to treat parkinsonism using music therapy coupled with conventional treatment. From these works, it was noticed the great improvement in the majority of the cases in the quality of life of the patient, as well as of the people that the patient lives, minimizing their suffering.
\end{abstract}

Keywords: Parkinson's disease; Music; Alternative tratament; Elders

\section{Introdução}

A doença de Parkinson (DP) é uma das doenças neurodegenerativas mais comuns entre a população, é uma doença crônica e progressiva, de etiologia idiopática (SEER et al., 2016). A prevalência da DP na população brasileira é de 150-200 casos por cem mil habitantes, sendo que, anualmente, vinte novos casos são atestados (CÔRTE; LODOVICI NETO, 2009).

\footnotetext{
${ }^{1}$ Discente do curso de enfermagem da Faculdade Independente do Nordeste Campus Vitória da Conquista.

Autor correspondente: fabrinarodrigues2@gmail.com;

${ }^{2}$ Docente adjunta ao curso de enfermagem da Faculdade Independente do Nordeste Campus Vitória da Conquista, Doutora em Ciências Sociais pela Pontificia Universidade Católica de São Paulo - PUC/SP
} 
Id on Line Revista Multidisciplinar e de Psicoloqia

Id on Line Multidisciplinary and Psycology Journal

Segundo Organização Mundial de Saúde, essa patologia afeta um em cada mil indivíduos, acima de 65 anos; e um em cada cem, após os 75 anos. A principal característica da patogênese associada à DP está relacionada a degeneração dos neurônios dopaminérgicos na substância negra compacta do mesencéfalo, o que resulta na perda excessiva de dopamina nos gânglios basais, resultando em desordens do movimento (SEER et al., 2016).

A sintomatologia motora está associada a bradicinesia, tremor de repouso, rigidez e distúrbios posturais, os quais ocasionam os sintomas motores de início tardio, como instabilidade e quedas posturais, congelamento da marcha, dificuldades de fala e deglutição (WORLD HEALTH ORGANIZATION, 2006).

Neste contexto, se encontra a necessidade de desenvolver técnicas de reabilitação inovadoras e eficazes no campo da neuro-reabilitação. Nos últimos anos, neurocientistas vêm pesquisando e estudando sobre a percepção e os efeitos da música no cérebro humano. A partir dos resultados obtidos dessas pesquisas foi possível delinear o impacto positivo da música na plasticidade cerebral, especificamente no sistema motor-sensorial (FRANÇOIS et al., 2015).

A musicoterapia é uma ciência recente, porém, é utilizada desde a antiguidade de diversas maneiras como medida preventiva, paliativa e, às vezes, até como terapêutica (OLIVEIRA et al., 2012). A musicoterapia, que no decorrer dos últimos anos vem se apresentando como um campo de pesquisa altamente promissor para a área da saúde, em suas inúmeras teorias, tem orientado práticas com resultados promissores no tratamento de patologias que afetam a capacidade física, cognitiva ou subjetiva das pessoas, como é o caso de alguns distúrbios neurodegenerativos, como por exemplo, a doença de Parkinson (CÔRTE; LODOVICI NETO, 2009).

Trata-se de uma terapia alternativa não verbal, que possibilita o aumento da autoestima de um indivíduo, além de promover interações em grupo, auxiliar no tratamento de doenças, proporcionando melhor qualidade de vida. Estes benefícios ocorrem através da influência da música, dos sons, movimentos, manuseio de instrumentos musicais, entre outros (OLIVEIRA et al., 2012). A musicoterapia pode ser ativa, quando o próprio paciente utiliza algum instrumento; ou passiva, quando o terapeuta utiliza-se da música para realizar o tratamento.

Apresentou-se como objetivo geral verificar, a partir de uma revisão sistemática sobre a importância desta prática alternativa de tratar melhor esta doença que acomete grande parte da população idosa. Para isso foram elencadas alguns objetivos específicos, como: apresentar 
a importância de práticas alternativas fundamentadas em elementos musicais, que podem funcionar como atividade terapêutica para pessoas com a doença de Parkinson, bem como, devem ser aplicadas com seriedade e competência pelos seus profissionais; Discutir e explicitar como a musicoterapia pode funcionar de forma eficiente como atividade terapêutica em pacientes acometidos da DP; Esclarecer quais as condições ou restrições suficientes e necessárias para a utilização da terapia em questão; Discutir os benefícios que a musicoterapia proporciona para pacientes acometidos, direta ou indiretamente.

\section{Metodologia}

Tendo em vista que, para alcançar com êxito os objetivos propostos numa pesquisa, tem-se como necessidade, de primeira instância, a organização de estratégias que indiquem os caminhos nos quais os pesquisadores deverão estar "trilhando" para o sucesso do seu estudo, o presente estudo tem por objetivo analisar como a musicoterapia pode auxiliar na melhor vivência do paciente com Parkinson.

A abordagem utilizada foi a pesquisa qualitativa que segundo Gil (1991 apud SILVA, 2005), considera que há uma relação dinâmica entre o mundo real e o sujeito, isto é, um vínculo indissociável entre o mundo objetivo e a subjetividade do sujeito que não pode ser traduzida em números.

Para realização deste estudo foi realizada uma pesquisa bibliográfica, que segundo Lakatos e Marconi (1992), é o levantamento de toda a bibliografia já publicada, em forma de livros, revistas, publicações avulsas e imprensa escrita. A sua finalidade é fazer com que o pesquisador entre em contato direto com todo o material escrito sobre um determinado assunto, auxiliando o cientista na análise de suas pesquisas ou na manipulação de suas informações. Foi feito todo o levantamento de material bibliográfico sobre a temática.

E exploratória, que segundo Gil (2008) tem o sentido de facilitar a compreensão do assunto, visto que, ao final de uma pesquisa exploratória, o assunto se torna mais conhecido, de modo a construir hipóteses. Como qualquer exploração, a pesquisa exploratória depende da intuição do explorador. 
A análise dos dados foi feita através do método análise de conteúdo, que de acordo com Bardin (2009), é um conjunto de técnicas de investigação que, através de uma descrição objetiva, sistemática e quantitativa do conteúdo manifesto das comunicações, tem por finalidade a interpretação destas mesmas comunicações.

O autor ainda diz que a análise divide-se em três etapas: pré-analise; exploração do material e tratamento dos resultados, inferência e interpretação. Pré-analise: é a fase de organização tem por objetivo operacionalizar e sistematizar as idéias iniciais de maneira a conduzir a um esquema preciso de desenvolvimento da pesquisa. Exploração do material: é a operação de analisar o texto sistematicamente em função das categorias formadas anteriormente.

Por fim, segundo Bardin (2009), o tratamento dos resultados, inferência e a interpretação: Os resultados brutos, ou seja, as categorias que serão utilizadas como unidades de análise são submetidas a operações estatísticas simples ou complexas dependendo do caso, de maneira que permitam ressaltar as informações obtidas. Após isto são feitas inferências e as interpretações previstas no quadro teórico e/ou sugerindo outras possibilidades teóricas.

\section{Doença de Parkinson}

O processo de envelhecimento é um processo natural de todas as espécies que se caracteriza como homem e dá-se segundo Mendes (2005) por “mudanças físicas, psicológicas e sociais que acometem de forma particular cada indivíduo com sobrevida prolongada."

É destacado por Moragas (1997 apud MENDES et al., 2005) o processo de envelhecimento está ligada à redução progressiva da sobrevivência destes indivíduos, muitas vezes se alinhando às alterações no papel social e o dia-a-dia destas pessoas. As doenças degenerativas se caracterizam como uma destas mudanças que impedem o mínimo bem-estar do paciente (SANTOS et al., 2008).

Dentre estas doenças, uma das mais recorrentes na população idosa é a doença de Parkinson, paralisia agitante ou ainda Parkinsonismo (SOUZA et al., 2011) descrita inicialmente por James Parkinson em 1817 na publicação An Essay On The Shaking Palsy. 
Apresenta 100-150 casos a cada 100.000 pessoas, atrás em número de casos em doenças degenerativas apenas para a doença de Alzheimer (BARBOSA; SALLEM, 2005).

Embora caracterizada pelos sinais cardinais de rigidez, acinesia, bradicinesia, tremor e instabilidade postural, muitas vezes é difícil para se caracterização desta doença, por ser uma doença multifatorial (SOUZA et al., 2011), a doença vem a aparecer nas proximidades dos anos 60 de idade, podendo acometer qualquer pessoa (BARBOSA; SALLEM, 2005).

\section{Causas}

Podemos caracterizar a doença de Parkinson como uma desordem neurodegenerativa, inicialmente caracterizada pela perda de neurônios dopaminérgicos na substância negra, pigmentação por melanina, que aumenta ao ponta em que a doença se torna mais crônica (PEDROSA, TIMMERMANN, 2013).

Neste caso a redução da ligação da dopamina nos seus receptores provocam alterações em estruturas básicas do cérebro, que estão ligados ao controle dos movimentos, causando os principais sintomas ligados à doença(VIVA BEM COM PARKINSON, 2015).

Outros casos como a utilização prolongada de fármacos para vertigens, tonturas e antipsicóticos e alguns remédios para hipertensão, podem apresentar tais sintomas, uma vez que aumentam a acetilcolina no neurônio ou reduzem as concentrações de dopamina (CABRAL, 2010). Ou ainda, pela alfa-sinucleína, ubiquitina e sinfilina-1 nas células neuronais de várias regiões cerebrais, destacando os corpúsculos de Lewy (PERFEITO; REGO, 2011)

Esta doença é tida como idiopática pela OMS. A palavra vem de duas palavras gregas idios e pathos que significam respectivamente do próprio e sofrimento, ou seja, uma doença que vem espontaneamente sem apresentar uma única etiologia ou ainda esta não possa ser caracterizada categoricamente (KAWANO-DOURADO; KAIRALLA, 2013).

Entretanto, algo comum a todos os pacientes é o estresse oxidativo, cujo pode ocorrer quando há desequilibrios entre o mecanismo de produção e de defesa antioxidativa. Diversos genes de forma indireta podem está ligados à doença como um todo de forma direta ou indireta podendo levar à morte celular programada caso necessário (SOUZA et al., 2011). 
A doença apresenta hoje alguns fatores ambientais e também genéticos que predispõem ao paciente à enfermidade, podendo ela ser estudada de forma genética de aporte mendeliano ou ainda por meios de susceptibilidade (SOCAL, 2008). No entanto, isto só foi descoberto a poucos anos pela análise pós-mortem de pacientes acometidos pela doença, principalmente no corpúsculo de Lewy (Figura 1).

Figura 1: Comparação entre um neurônio saudável e o neurônio acometido pela doença, identifucando os corpúsculos de Lewy

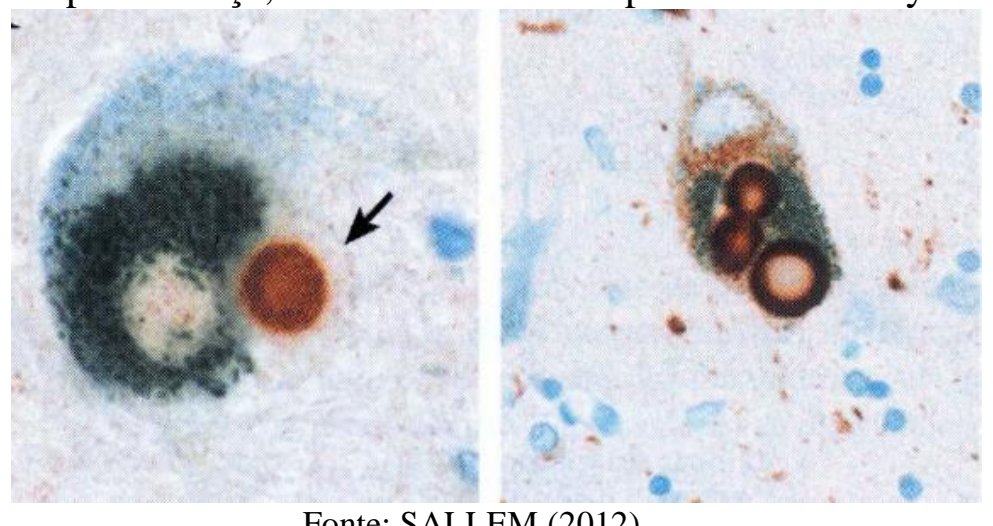

Fonte: SALLEM (2012)

Entretanto, alguns estudos mostram que nem só os corpúsculos de Lwy causam o Parkinsonismo, uma cas causas pode ser a genética do indivíduo. Desde meados de 1997, os autores Polimeropoulos e colaboradores, estudaram um gene nomeado de PARK1, por está relacionado à doença, atualmente cerca de 9 genes PARK são estudados no mundo, sendo este grupamento de genes recessivo e autossômico. Outros genes autossômicos dominantes (genes SCA1, SCA2, SCA3, SCA6 e SCA7) e o gene de suscetibilidade (gene GBA) (SOCAL, 2008).

Outro fato importante sobre esta doença é que ela pode está ligada ao aparecimento de outras doenças degenerativas ou ainda sobre a ingestão de substâncias exógenas que apresentam degeneração da região da substância negra do cérebro (SOUZA et al., 2011).

Outra hipótese para sua origem cada vez maior é o efeito tóxico sobre os neurônios dopaminérgicos da via nigro-estriatal por herbicidas à base de 1-metil-4-fenilpiridinium ou paraquat, rotenona e compostos com manganês, por ser inibidor específico do complexo mitocondrial I, que forma os corpúsculos de Lewy (SOCAL, 2008). 


\section{Sinais Sintomas}

A doença para melhor caracterização é dividida em 6 estágios progressivos (SOUZA et al., 2007), esta escala é conhecida como Escala de Hoehn \& Yahr. No primeiro grau, há comprometimento do núcleo dorsal dos nervos glossofaríngeo e vago, localizados nas regiões dopaminérgicas, além da zona reticular intermediária e do núcleo olfatório anterior.

No estágio 2, adiciona a deterioração dos núcleos reticulares gigantonuclear, da rafe e do complexo do lócus cerúleos. No estágio 3, ocorre a compactação da substância negra do mesencéfalo. Nas fases seguintes, as regiões prosencefálicas, segundo Souza et al. (2007) ainda “do mesocórtex temporal e de áreas de associação do neocórtex e neocórtex pré-frontal”, áreas pré-motoras e área motora primária respectivamente.

É percebido também que a doença se inicia nos neurônios motores destacando os sinais cardinais da doença de parkinson. Sendo eles: rigidez, tremor, bradicinesia e instabilidade postural. Diversos autores atribuem estes sinais à disfunção do sistema nigro-estriatal, redução das concentrações de dopamina que serão ligados aos receptores dopaminérgicos presentes nos gânglios da base, no corpo estriado (LIMA, 2009; PINHEIRO et al, 2016; PERFEITO; REGO, 2011).

Ao analisar a processo de disfunção do circuito dos gânglios da base, pode-se perceber a redução significativa de inibição do segmento lateral do globo pálido sobre o núcleo subtalâmico, e/ou ainda o aumento da excitação do núcleo subtalâmico sobre o segmento medial do globo pálido, levando à síndrome rígido-acinética, havendo falta de igualdade na distribuição de impulsos, progredindo para vários músculos (LIMA, 2015).

Os sinais de bradicinesia, por muitas vezes é citada ocasionada pela ausência de dopamina no estriado, por isso, ocorre o desequilíbrio entre a inibição e excitação de neurotransmissores, desencadeando ao paciente movimento tranca em uma direção dificultando a progressão dos passos, o que deixa ele lento (SOUZA et al., 2011).

Quanto à postura característica da curvatura da coluna e a cabeça e o tronco fletidos dificultando a postura, isso ocorre pois, segundo Cabral (2010, p. 117). 
A marcha parkisoniana apresenta-se por passos curtos, rápidos e arrastados, sem a participação dos movimentos dos braços, sendo principalmente decorrente do "aumento da cifose torácica com uma flexão de joelhos, onde o corpo adota uma postura que favorece a anteriorização do centro de gravidade" (CABRAL, 2010, p. 117).

A síndrome ainda apresenta outras consequências clinico-patológica ligados aos neurônios serotonérgicos e noroadrenergicos e suas reações bioquímicas, muito se cogita ser desencadeado por fatores genéticos e/ou ambientais, isto justificaria o aparecimento de problemas não-motores, como problemas de sono, pernas inquietas, disfunção cognitiva e depressão, repercutindo em uma baixa qualidade de vida, tornando a DP ainda mais incapacitante e reduzindo a expectativa de vida (CABRAL, 2010, p. 117).

\section{Tratamento Farmacológico}

O parkinsonismo pode ser considerada uma doença idiopática, AVC ou infecção viral, ou ainda, por drogas, como a reserpina e a clorpromazina. Todos os casos degeneram a região negra do cérebro, entretanto não se sabe a justificativa pela degeneração dos neurônios dopaminérgicos ainda permanece desconhecida (PINHEIRO et al., 2016).

Além da doença de parkinson outras doenças apresentam sinais parecidos à patologia. Entretanto estes sinais também podem ser apenas um efeito colateral do fármaco, neste grupo são incluídos os antipissicóticos e os antieméticos (CAMARGO et al., 2017).

Segundo Cabral (2010) atualmente alguns grupos de fármacos são utilizados para o tratamento do parkinsonismo são elas:

a) drogas que substituem a dopamina (levodopa) juntamente com inibidores da dopa descarboxilase de ação periférica (carbidopa e benserazida); a própria dopamina não é apropriada para o tratamento, pois não atravessa a barreira hemato-encefálica

b) drogas que imitam a ação da dopamina - agonistas dos receptores dopaminérgicos (bromocriptina, pergolida, lisurida);

c) inibidores da MAO-B (selegilina);

d) drogas que liberam dopamina (amantadina);

e) antagonistas da acetilcolina (benztropina) (CABRAL, 2010, p. 178) . 


\section{Musicoterapia}

A música ela pode ser entendida como uma arte que se baseia na liberação e propagação de sons de forma simultânea e sucessiva, prezando pelo ordenamento, equilíbrio e proporcionalidade durante o tempo da melodia, podendo manifestar-se dentro de um contraponto gerando harmônia (NOBRE, 2006).

Para entender melhor a música é interessante também sabermos alguns conceitos para maiores entendimentos a frente sobre as partes que componham uma música, segundo Nobre (2006, p. 2) são:

1) MELODIA- É a combinação dos SONS SUCESSIVOS (dados uns após outros). É a concepção horizontal da Música.

2)HARMONIA-É a combinação dos SONS SIMULTÂNEOS (dados de uma só vez). É a concepção vertical da Música.

3)CONTRAPONTO- É o conjunto de melodias dispostas em ordem simultânea. É a concepção ao mesmo tempo horizontal e vertical da Música.

4)RÍTMO-É a combinação dos valores tempo (Nobre, 2006, p. 2) .

Outro ponto importante são as figuras rítmicas, que indicam a duração dos sons e silêncios proporcionalmente, sendo as fusas as menos silenciosas e os semibreves os que apresentam mais tempo em silêncio, entre eles estão as semicolcheias, as colcheias, as semínimas e mínimas, sendo que cada uma na escala apresenta $1 / 2$ da escala anterior como apresentada na figura 2 (GUSMÃO, 2012).

Quanto às notas musicais apresenta-se 7 principais, Dó, Ré, Mi, Fá, Sol, Lá e Si, que unidas foram a escala, elas representam as variações de altura de um som propagado, foram pela primeira vez descritos por Guido d'Arezzo (992-1050 d.C.), monge do século X, através do hino à São João (PRIOLLI, 2006).

Segundo Nobre (2006) a música apresenta um grande fator cultural, sendo possível separar a história e a geografia pelos diferentes ritmos, outro ponto que a secretaria atribui é que a música consegue produzir sensações físicas nos organismos. 
Figura 2: Figuras rítmicas em compasso

o Semibreve

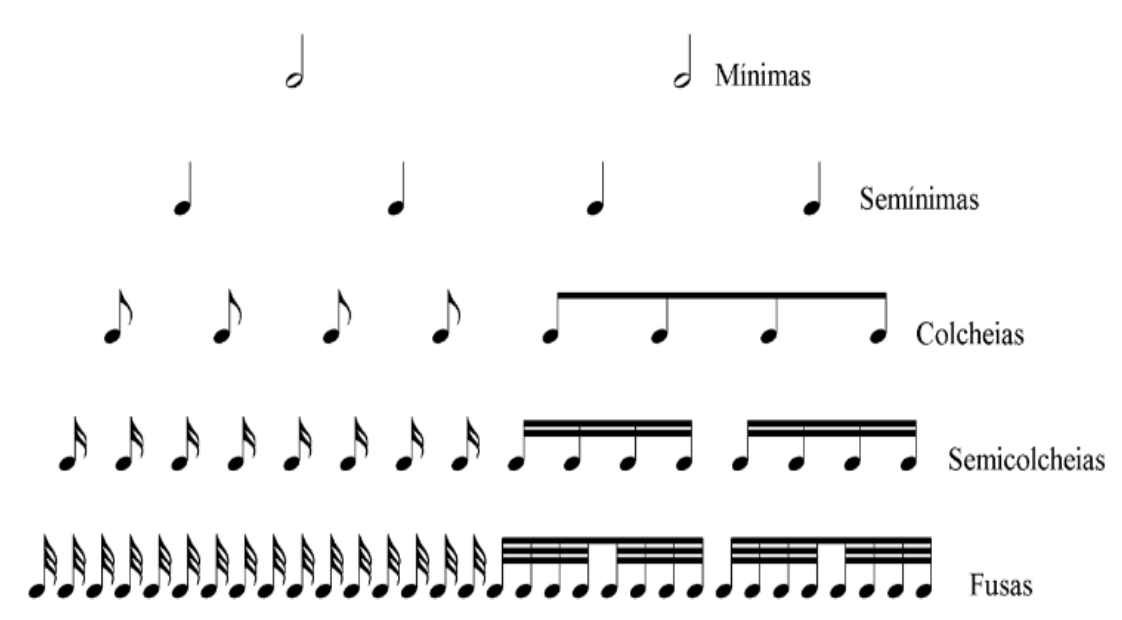

Fonte: Gusmão (2012)

Pensando nisso, podemos destacar a música como forma de reduzir ou mesmo tratar um problema de saúde corporal ou psicológico, esta faceta da música é conhecido como musicoterapia (ambas palavras têm sua etimologia do grego no qual Música - Técnica das musas; Terapia - Prestar cuidados dos médicos, tratar).

Por definição a musicoterapia segundo Silva (2017) é

\begin{abstract}
Musicoterapia é a utilização profissional da música e seus elementos, para a intervenção em ambientes médicos, educacionais e cotidiano com indivíduos, grupos, famílias ou comunidades que procuram otimizar a sua qualidade de vida e melhorar suas condições físicas, sociais, comunicativas, emocionais, intelectuais, espirituais e de saúde e bem estar. Investigação, a educação, a prática e o ensino clínico em musicoterapia são baseados em padrões profissionais de acordo com contextos culturais, sociais e políticos (SILVA, 2017).
\end{abstract}

Segundo Magalhães (2011), Ferreira (2005) e Oliveira e Gomes (2014) este tipo de tratamento não é recente, uma vez que, desde a medicina clássica grega já era utilizada como forma de tratar certas doenças com música.

O uso da música no combate às enfermidades remonta a épocas primitivas da história da humanidade. Na Cultura Ocidental, os antigos gregos desenvolveram um processo de cura por meio do uso de intervalos e ritmos da melodia; considerava-se que a música era a primeira forma de sabedoria desenvolvida pelo homem, sendo assim, por meio de 
certos ritmos e melodias julgava possível a cura para as paixões humanas e hábitos considerados não viáveis. Assim, a desarmonia interna dos humores do corpo provocava patologias, as quais poderiam ser curadas pela música, devido ao seu poder de restaurar a ordem e a harmonia (FEREIRA, 2005, p. 12).

Hipócrates foi chamado o Pai da Medicina, podemos reconhecer em Platão e Aristóteles os precursores da Musicoterapia. Platão recomendava a música para a saúde da mente e do corpo, e para vencer as angústias fóbicas. Aristóteles descrevia seus benéficos efeitos nas emoções incontroláveis e para provocar a catarse das emoções (OLIVEIRA; GOMES, 2014, p. 756)

Além dos gregos, os romanos, os árabes e os israelitas também utilizavam nos tratamentos de doenças, utilizando procedimentos pré-científicos e muitas vezes místicos, tratando as enfermidades como desarmonias ou ainda pestes contra alguma desventura humana (FERREIRA, 2005).

Em outros termos, é uma ciência que estuda as manifestações sonoras acompanhadas de seus elementos e os efeitos decorrentes da interação com o ser humano, suas manifestações (CUNHA; VOLPI, 2008). No âmbito prática desta ciência tenta-se aplicar a música como uma investigação científica no qual deseja ver as alterações dos indivíduos (CARDOSO, 2010). Nela é possível, promover, prevenir, e reabilitar da saúde física, psíquica, emocional e social dos pacientes (CUNHA; VOLPI, 2008)

Segundo Sekeff (2002 apud CARDOSO, 2010) a música apresenta sua existência como terapia para males desde 1500 a.C., para este autor, "a evolução deu-se a nível do tipo de música, das crescentes aplicações e também na forma de perceber os seus benefícios" (CARDOSO, 2010, p. 12). Entretanto apenas na década de 1940 que a musicoterapia passou a ser estruturada (PASSARINI, 2013). Há muito tempo a musicoterapia vem sendo utilizado para tratar desequilíbrios nervosos, exercem influência positiva sobre os sistemas, também tratamentos de dependência de álcool e outras drogas (VELLEJO, 2010).

É possível ao se ouvir certas melodias e esta ter a mesma função que um remédio, sendo tão eficaz quantos estes e suas formulações. Sabe-se que a música faz um grande bemestar a quem ouve. Diversos estudos já vem mostrando melhoras em casos clínicos de asmas, câncer, problemas psíquicos, doenças progressivas, distúrbios de comunicação e de memória, entre outros problemas de saúde (MINHA VIDA, 2007).

Para a Bibliomed (2009) esta metodologia apresenta diversas vantagens que auxiliam em diversos tratamentos. 
O musicoterapeuta pode utilizar apenas um som, recorrer a apenas um ritmo, escolher uma música conhecida e até mesmo fazer com que o paciente a crie sua própria música. Tudo depende da disponibilidade e da vontade do paciente e dos objetivos do musicoterapeuta. A música ajuda porque é um elemento com que todo mundo tem contato. Através dos tempos, cada um de nós já teve, e ainda tem, a música em sua vida (BIBLIOMED, 2009).

Segundo estudos com a musicoterapia, a música utiliza certos "hemisférios cerebrais", para que assim, o paciente apresente "equilíbrio entre o pensar e o sentir, resgatando a" 'afinação' do indivíduo, de maneira coerente com seu diapasão interno" (BIBLIOMED, 2009). De forma que, os sons melodiosos funcionem diretamente no lado emocional, a harmonia, o racional, a inteligência e as respostas motoras do corpo (FERREIRA, 2005).

\section{Doenças e Transtornos Tratados com a Musicoterapia}

Atualmente diversos trabalhos mostram a utilização, aplicação e a importância da musicoterapia no tratamento de doenças e transtornos em diversas fases da vida, para os especialistas é claro que não há diferença de idade, podendo agir sobre bebês até pessoas nas mais tenras idades (FREITAS, 2016).

Os estudos a partir da década de 1980 mostram que há três tipos de memórias que são ativadas com a musicoterapia para problemas de cunho psíquico, são elas a

[...] a memória declarativa, que permite lembrar uma peça de música que ouvimos, a memória processual, que permite fazer movimento corporal em sintonia com a música (bater palmas, bater o pé ao ritmo da música) e a memória do tipo familiar, onde existe um reconhecimento e uma identificação da música sem saber o título ou o compositor (BRIGHT,1997 apud MAIA, 2014).

A musicoterapia já vem sendo utilizada como forma de primeira aproximação a pessoas com esquizofrenia (COSTA; VIANNA, 1984) e autismo (SAMPAIO; LOREIRO; GOMES, 2015). Também pode ser aplicado em casos de problemas emocionais, atitudes, energia dinâmica psíquica, que será o esforço para modificar qualquer patologia física ou psíquica (BERTOCINI; SARTONI, 2015).

Segundo Manfio e Santos (2016) transtornos como o TDAH, o estresse, autismo e também AVC. 
- Estresse: "A pessoa deve identificar a origem desse problema e tomar algumas atitudes, que variam: ficar em silêncio, ouvir uma música boa de seu gosto pessoal que induza o relaxamento, seja instrumental ou não. Outra opção para auxiliar no alívio é tocar um instrumento, como a bateria”. - Transtorno do Déficit de Atenção com Hiperatividade (TDAH): "Além dos métodos terapêuticos, o paciente pode aprender a tocar algum instrumento musical, pois isso irá contribuir no tratamento". - Acidente vascular cerebral (AVC): "A música pode colaborar com a reabilitação social, emocional, física e, principalmente, da linguagem, porque a pessoa voltará a se expressar naturalmente". - Autismo: "Por meio da música, vemos, aos poucos, que as pessoas com autismo vão adquirindo uma maior expressividade, se organizando melhor, se acalmando e ampliando a atenção, o que resulta no processo da aprendizagem de novas capacidades" (MANFIO; SANTOS, 2016).

Os diversos estilos e ritmos musicais produzem trabalhos diferenciados e resultantes corporais diferentes. A música clássica como, as sinfonias, J. S. Bach são usadas para melhorar o aprendizado e a memória. Para pacientes com depressão são usados músicas de Rossini, Guilherme Tell e Wagner, Walkirias. Os sons de Strauss aumentam o relaxamento de seus ouvintes durante pertos. A energia e o pulso das marchas podem ser utilizados em pacientes convalescentes, contrário ao rock que diminui o pulso, os espasmos e o ritmo da respiração (MANFIO; SANTOS, 2016).

Segundo o Carraro (2011) a utilização de música na terapia de Alzheimer com uso da musicoterapia está ajudando pacientes a terem melhor bem-estar.

\begin{abstract}
Um bom exemplo disso tem sido o uso da musicoterapia, no auxílio do tratamento da doença de Alzheimer. Doença de caráter progressivo e degenerativo tem, entre seus primeiros sinais, o esquecimento, a dificuldade de estabelecer diálogos, as mudanças de atitude e a diminuição da concentração e da atenção. A musicoterapia ajuda a estimular a memória, a atenção e a concentração, o contato com a realidade e o esforço da identidade. Trabalha-se ainda a estimulação sensorial, a autoestima e a expressão dos sentimentos e emoções (CARRARO, 2011).
\end{abstract}

Sendo assim, outros problemas de saúde da terceira idade podem ser amenizados com o uso da musicoterapia associado à terapia convencional. O Parkinsonismo já é tratado pela interação destes dois métodos. 


\section{Parkinsonismo e a Musicoterapia como Método Terapêutico}

Diversos métodos são propostos atualmente para se tratar do Parkinsonismo, segundo Fragnani e colaboradores (2016) as atividades físicas e lúdicas são medidas sustentáveis e atende a demanda da saúde pública nacional, por ser feito em grupo ou ainda individualmente quando necessário. Diversos autores informam que a utilização de terapias que não deixem o idoso em situações de terapia deixam-os desmotivados, uma vez que, ele já está muitas vezes deprimido e debilitados, há relatos feitos pelos pacientes no qual eles apenas saem de casa para as casas de apoio para pegar o remédio, sendo assim reduzindo seu contato social, então a musicoterapia pode servir tanto para socializar quanto para tratar da enfermidade (MAIA; 2014, CAVALIERE, 2014; HAZARD, 2008)

Segundo a ONG viva bem com parkinson (2015) o desenvolvimento de hobbies que utilizem a música estimulam os sentidos do paciente, pois minimizam os efeitos de ordem motora quanto os efeitos não-motores. Podendo ser em corais, individual, ou ainda tocando algum instrumento para se ligar à músicas que o faça bem, entretanto o método deve ser utilizado sem retirar a medicação (VIVA BEM COM PARKINSON, 2015). Segundo Cavaliere (2014) “A Musicoterapia promove inicialmente um resgate da auto-estima do parkinsoniano, e em seguida pode associar segmentos corporais como membros, tronco, marcha, alongamentos, fortalecimento muscular, cintura, abdome, etc."

Estudos feitos em 2000, com o intuito de observar a importância da musicoterapia para os sintomas dos pacientes com a doença, viu-se que diversos aspectos dos pontos analisados apresentaram melhorias (PACCHETTI et al, 2000). Os estudos de Fragnani e colaboradores (2016), mostraram redução nos sintomas da doença, equilíbrio, mobilidade e independência funcional dos pacientes testados com Yoga e musicoterapia.

Segundo Cervera (2010), podemos entender o ritmo como a base da música para a terapia de tratamento para a doença de Parkinson permite assim, respostas positivas do estado físico, psicológico, mental e espiritual. Esta autora ainda cita que a música está diretamente ligado ao ritmo vital e mental, desta forma, podemos considerar os ritmos como a base de todas as manifestações vitais, sendo ele usado para, o ordenamento, na medida em movimento e forma pessoal para executar esse movimento. 
Para Lodovici Neto (2011) em entrevista à PUC-SP quanto aos benefícios da musicoterapia para o idoso com Parkinsonismo, ele respondeu que:

\begin{abstract}
Musicoterapia tem o papel essencial de vivificar as funções ditas mnêmicas (de memória), assim como as demais funções cognitivas, a ponto de, a partir da produção sonoro-musical, contribuir na elaboração de conteúdos mentais mais complexos, o que faz com que o doente resgate a memória desejada, que consiga o retorno de movimentos corporais comprometidos, que se sinta um ser produtivo e harmonizado com sua idade cronológica. Acrescente-se ainda que a Musicoterapia auxilia a pessoa idosa portadora da Doença de Parkinson a orientar-se, restabelecendo as coordenadas de tempo e espaço; a relaxar, no caso de insegurança ou ansiedade; expressar-se melhor, quando existem problemas de comunicação; potencializar as funções físicas e mentais com problemas e reforçar a autonomia pessoal, através da música; receber uma maior atenção, um reconhecimento e um sentido de seu próprio valor como sujeito, pois, por exemplo, ao retomar músicas da infância ou juventude, enfim, músicas que afetaram beneficamente sua vida, ao participar de sua execução, elas farão emergir sua criatividade musical, lhe trarão uma renovação em seu estado de ânimo, auxiliando a recompor corpo e espírito (LUDOVICI NETO, 2011).
\end{abstract}

Segundo Hazard (2008) em suas unidades experimentais de trabalho de integração funcional no qual ele avaliava após sessões terapêuticas com música os pacientes com Parkinson apresentavam melhora na marcha de treinamento e melhora no equilíbrio do corpo nas transferências paralelas e formação de um ponto a outro, por meio de um metrónomo com e sem música de fundo, percebeu que a pulsação rítmica auxiliam o paciente a se reabilitar.

\title{
Considerações Finais
}

A música, uma das mais belas artes, além de apenas um som, uma emissão de onda, pode ser utilizada como uma forma de alternativa para acalentar, unir as pessoas, lembrar coisas, usando estas características, a música pode ser usada como uma terapia alternativa coadjuvante à terapia convencional para diversas doenças, destacando neste trabalho o parkinsonismo, uma vez que, a cada senso percebe-se que a população idosa está aumentando e sendo assim a doença pode acarretar grande percentagem da população daqui alguns anos.

Como foi possível perceber, o uso da musicoterapia como forma de auxiliar no bemestar e idosos já vem sendo consolidada na medicina, assim, aliada à terapia convencional pode promover melhor sociabilidade entre os participantes aliado às criatividades musicais 
individuais ou em grupo, apresentando melhor minimização ou superação dos problemas do paciente com Parkinsonismo.

A essência deste tratamento alternativo e coadjuvante é tornar a prática algo para compartilhar entre as pessoas do recinto, levando os senhores e senhoras para um mundo em que ele esteja presente no momento integralmente. Entretanto, esta mudança não é só sentida pelos pacientes, mas a todos que o cercam, de forma equilibrada, se exercitando harmonicamente.

Esta revisão analítica apresentou resultados nos quais apontaram que o uso do ritmo na reabilitação de pacientes com a doença de parkinson é significativo em diversos casos já descritos na literatura. A utilização desta técnica está sendo cada vez mais empregada nas terapias, significando maiores formas de condicionar aos pacientes melhor bem -estar.

\section{Referências}

BARBOSA, E.R.; SALLEM, F.A.Z. Parkinson's disease: diagnosis. Rev Neurociências, São Paulo, v. 13, n. 3, p. 158-165, 2005. Disponível em: <

http://www.revistaneurociencias.com.br/edicoes/2005/RN\%2013\%2003/Pages\%20from\%20R N\%2013\%2003-8.pdf >. Acesso em 20 abr. 2017.

BARDIN, L. Análise de Conteúdo (L. de A. Rego \& A. Pinheiro, Trads.). 70 ed. Lisboa Portugal: LDA, 2009, 281f.

\section{BERTONCINI, D.; SARTORI, V. Musicoterapia é alternativa no tratamento para combate à depressão. 2015 . Disponível em: $<$ https://cienciaetec.wordpress.com/2015/04/27/musicoterapia-e-alternativa-no-tratamento- para-combate-a-depressao/>. Acesso em: 27 abr. 2017.}

BRASIL. Constituição da República Federativa do Brasil. Diário Oficial da União, Brasília, 5 out. 1988. Disponível em: <http://www.planalto.gov.br/>. Acesso em: 25 abr. 2017.

BRIGHT, R. Music Therapy and the dementias: Improving the Quality of Life. 2. ed. St Louis: MMB, 1997. $209 \mathrm{f}$.

CABRAL, M. A.. Anotações em Farmacologia e Farmácia clínica. 2010. Disponível em: $<$ http://farmacolog.dominiotemporario.com/doc/Anotacoes_em_Farmacologia.pdf $>$. Acesso em: 28 abr. 2017. 
CAMARGO, C. H. F.; SERPA, R.A.; MATNEI, T.; SABATINI, J. S.; TEIVE, H.A.G. The perception of apathy by caregivers of patients with dementia in Parkinson's disease. Dementia e Neuropsychologia, Ponta Grossa, v. 10, n. 4, p.339-343, jan. 2017. Mensal. Disponível em: <https://www.researchgate.net/publication/311678752>. Acesso em: 26 abr. 2017.

CARDOSO, A.J.S. A utilização da musica como coadjuvante terapêutico na saúde mental e psiquiátrica. Trabalho de conclusão de curso (TCC) - Licenciatura em Enfermagem, Faculdade de Ciências da Saúde, Universidade Fernando Pessoa (UFP), Porto, 2010. 90f.

CARRARO, W.N. (Jaragua do Sul). Centro Assistencial Eurípedes Barsanulfo. Musicoterapia. $2011.2017 . \quad$ Disponível em: <https://caebjaragua.wordpress.com/category/estudos/>. Acesso em: 28 abr. 2017.

CARVALHO, C. R. A.; HENNINGTON, E. A. A abordagem do envelhecimento na formação universitária dos profissionais de saúde: uma revisão integrativa. Rev. bras. geriatr. gerontol., Rio de Janeiro, v. 18, n. 2, p. 417-431, 2015.

CAVAliere, G. J. A Musicoterapia aplicada na doença de Parkinson. 2014. Disponível em: <http://www.carlosmosquera.com.br/2609/>. Acesso em: 27 abr. 2017.

CERVERA, D. P. P.; PARREIRA, B. D. M.; GOULART, B. F. Educação em saúde: percepção dos enfermeiros da atenção básica em Uberaba (MG). Ciência \& Saúde Coletiva, Rio de Janeiro, v. 16, supl. 1, p. 1.547-1.554, 2011. Disponível em: http://www.scielo. br/pdf/csc/v16s1/a90v16s1.pdf. Acesso em: 28 abr. 2017.

CÔRTE, B.; LODOVICI NETO, P. Music therapy on Parkinson disease. Ciencia \& saude coletiva, São Paulo, v. 14, n. 6, pp. 2295-304, 2009. Disponível em: < http://www.scielo.br/pdf/csc/v14n6/38.pdf > Acesso em: 28 abr. 2017.

COSTA, C. M., \& VIANNA, M. N. Musicoterapia:Música e Linguagem nas esquizofrenias. Revista do Corpo e da Linguagem, Rio de Janeiro, v. 2, n. 6, p. 153-157,1984.

CUNHA, R.; VOLPI, S. A prática da musicoterapia em diferentes áreas de atuação. Rev. Cient.: FAP, Curitiba, v. 3, n. 1, pp. 85-97, 2008.

FERREIRA, T. T. Música para se Ver. 2005. 115 f. Monografia (Especialização) - Curso de Comu Nica çã O Social, Facom, Universidade Federal de Juiz de Fora, Juiz de Fora, 2005. Cap. 1. Disponível em: <http://www.ufjf.br/facom/files/2013/04/TFerreira.pdf>. Acesso em: 26 abr. 2017.

FRAGNANI, S. G.; SOUSA, A.; LOPES, K.; NERY, T.; WENER, E.; BEZERRA, P. Proposta de um Programa de Prática Em Grupo Composto por Fisioterapia, Yoga e Musicoterapia para Pacientes com Doença de Parkinson. Revista Brasileira de Neurologia, [S.1.], v. 52, n. 3, nov. 2016. ISSN 2447-2573. Disponível em: <https://revistas.ufrj.br/index.php/rbn/article/view/5147>. Acesso em: 19 Mai. 2017. 
FRANÇOIS, C.; GRAU-SÁNCHEZ, J.; DUARTE, E. RODRIGUEZ-FORNELLS, A. Musical training as an alternative and effective method for neuro-education and neuro-rehabilitation. Frontiers in Psychology. v. 6, n.475, p.1-15.

FREITAS, M. R. M. Musicoterapia e Psicanálise caminham juntas no tratamento de doenças e problemas psicossomáticos. 2016. Disponível em: $<$ http://ovigilanteonline.com/musicoterapia-e-psicanalise-caminham-juntas-no-tratamento-dedoencas-e-problemas-psicossomaticos/>. Acesso em: 28 abr. 2017.

GIL, A. C. Como elaborar projetos de pesquisa. 3. ed. São Paulo: Atlas, 1991. Como elaborar projetos de pesquisa. 4. ed. São Paulo: Atlas, 2008.

GUSMÃO, P. Teoria Elementar da Música: Teoria e Percepção Musical. 2012. Disponível em: <http://200.18.45.28/sites/musica/images/teoria_elementar.pdf.>. Acesso em: 27 abr. 2017.

HAZARD, S. Musicoterapia en enfermedad de Parkinson. 2008. Disponível em: <https://voices.no/index.php/voices/article/view/419/343>. Acesso em: 26 abr. 2017.

KAWANO-DOURADO, L.; KAIRALLA, R.A.; CARVALHO, C.R.R. Fibrose pulmonar idiopática: uma atualização. Pulmão RJ, São Paulo, v. 22, n. 1, p. 33-37 2013. Disponível em: $<$ http://www.sopterj.com.br/profissionais/_revista/2013/n_01/08.pdf >. Acesso em: 26 abr. 2017.

LAKATOS, E. M.; MARCONI, M. A. Metodologia do trabalho científico. 4.ed. São Paulo: Atlas, 1992.

LIMA, M. M. S. O papel do sistema dopaminérgico nigroestriatal na neurobiologia do sono. 2009. $221 \mathrm{f}$. Tese (Doutorado) - Curso de Farmacologia, Escola Paulista de Medicina, Universidade Federal de São Paulo, São Paulo, 2009. Cap. 1.

LODOVICI NETO, P. A musicoterapia como tratamento coadjuvante à Doença de Parkinson. 2006. 224 f. Dissertação (Mestrado em Gerontologia) - Pontifícia Universidade Católica de São Paulo, São Paulo, 2006.

MAGALHÃES, Vítor Amílcar. C ontributo da M usicoterapia para a Inclusão de Alunos com Deficiência Mental na Escola. 2011. 115 f. Dissertação (Mestrado) - Curso de Mestrado em Ciências da Educação, Departamento de Econ Omia, Gestão e Ciências Sociais, Universidade CatÓlica Portuguesa, Viseu, 2011. Cap. 1.

MAIA, A. R. L. Despertar na demência: musicoterapia e os problemas associados da demência no i doso i nstitucionalizado. 2013. 129 f. Dissertação (Mestrado) - Curso de Musicoterapia, Instituto de Psicologia e Ciências da Educação, Universidade Lusíada de Lisboa, Lisboa, 2013. Cap. $1 . \quad$ Disponível em: 
<http://repositorio.ulusiada.pt/bitstream/11067/825/1/mmt_ana_maia_dissertacao.pdf>. Acesso em: 26 abr. 2017.

MANFIO, V.; SANTOS, V. Musicoterapia: a música como tratamento para doenças. 2016. Disponível em: <https://www.altoastral.com.br/musicoterapia-musica-tratamento/>. Acesso em: 27 abr. 2017.

MENDES, M.R.; GUSMÃO, J.L.; FARO, A.C.; LEITE, R.C. The social situation of elderly in Brazil: a brief consideration. Acta Paul Enferm, São Paulo, v. 15, n. 4, p. 422-426, 2005.

MENTAL HEALTH (Estados Unidos da América). World Health Organization.

Neurological Disorders: Public Health Challenges. 2006. Disponível em:

<http://www.who.int/mental_health/neurology/neurodiso/en/>. Acesso em: 27 abr. 2017.

MINHA VIDA. Musicoterapia cura doenças e promove o bem-estar. 2007. Disponível em: $<$ http://www.minhavida.com.br/bem-estar/materias/807-musicoterapia-cura-doencas-epromove-o-bem-estar>. Acesso em: 26 abr. 2017.

MORAGAS R.M. Gerontologia social: envelhecimento e qualidade de vida. São Paulo: Paulinas; 1997. 228f.

NOBRE, J. Projeto Fortalecimetno Musical: APOSTILA DE TEORIA MUSICAL. 2006. Disponível em: <http://www2.secult.ce.gov.br/Recursos/PublicWebBanco/Partituraacervo/Apt000002.pdf>. Acesso em: 26 abr. 2017.

OLIVEIRA, C. C.; GOMES, A. M. C. Breve História da Musicoterapia, suas Conceptualizações e $\quad$ Práticas. 2014. Disponível $<$ http://repositorium.sdum.uminho.pt/bitstream/1822/39982/3/S livro SPCE 2015 PCE2_EIXOS_BOOK CC (2).pdf>. Acesso em: 26 abr. 2017.

OLIVEIRA, G. C.; LOPES, V. R. S.; DAMASCENO, M. J. C. F. A contribuição da musicoterapia na saúde do idoso. Cadernos Unifoa, Volta Redonda, v. 20, n. 1, p.85-94, dez. 2012.

ORGANIZAÇÃO MUNDIAL DA SAÚDE -OMS. Active Ageing - A Police Framework. A Contribution of the World Health Organization to the second United Nations World Assembly on Aging. Madrid, Spain, 2002.

PACCHETTI C.;MANCINI, F.; AGLIERI, R.; FUNDARÒ, C.; MARTIGNONI, E.; NAPPI, G. Active Music Therapy in Parkinson's Disease: An Integrative Method for Motor and Emotional Rehabilitation. Psychosomatic Medicine: Journal of Biobehavioral Medicine, Pávia - Itlália, v. 62, n. 3, p. 386-393, 2000. 
PASSARINI, L. A musicoterapia atuando na qualidade de vida do idoso institucionalizado: caminhando pela psicogerontologia. .2013. Disponível em: < http://www.portaldoenvelhecimento.org.br/artigos/artigo294.htm >. Acesso em: 27 abr. 2017.

PEDROSA, D.J.; TIMMERMANN, L. Review: management of Parkinson's disease. Neuropsychiatric Disease and Treatment, Köln - Germany, v. 9, n. 1, p. 321-340, 2013.

PERFEITO, R.; REGO, A.C.; Papel da alfa-sinucleína e da disfunção mitocondrial associada à doenca de Parkinson. Rev. Neurosci., Coimbra, v. 20, n. 2, p. 273-284, 2012.

PINHEIRO, R. S. A.; ALVES, N. T.; ALMEIDA, A. A. F. Effectiveness and limitations of vocal therapy in Parkinson's disease: a literature review. Rev. CEFAC, São Paulo, v. 18, n. 3, p. 758-765, 2016. Disponível em: <http://www.scielo.br/scielo.php?script=sci_arttext\&pid=S1516$18462016000300758 \& \operatorname{lng}=$ en\&nrm=iso $>$. Acesso em: 29 abr. 2017.

PRIOLLI, M. L. M. Princípios básicos da música para a juventude. 48. ed. Rio de Janeiro: Casa Oliveira de Música Ltda, 2006. 146 p.

SALLEM, Flávio Sekeff. Genética da doença de Parkinson. 2012. Disponível em: <http://neuroinformacao.blogspot.com.br/2012/10/genetica-da-doenca-de-parkinson.html>. Acesso em: 25 abr. 2017.

SAMPAIO, R. T.; LOUREIRO, C. M. V.; GOMES, C. M. A. A Musicoterapia e o Transtorno do Espectro do Autismo: uma abordagem informada pelas neurociências para a prática clínica. Per musi, Belo Horizonte, n. 32, p. 137-170, 2015.

SANTOS, M. G. PEGORARO, M.; SANDRINI, F.; MACUCO, E. C. Fatores de risco no desenvolvimento da aterosclerose na infância e adolescência. Arq. Bras. Cardiol., São Paulo, v. 90,n. 4, p. 301-308, 2008.

SEER, C.; LANGE, F.; GEORGIEV, D.; JAHANSHAHI, M.; KOPP, B. Event-related potentials and cognition in Parkinson's disease: An integrative review. Neuroscience and Biobehavioral Reviews, Hannover, - Alemanha, v. 71, n. 1, p. 691-714, 2016.

SEKEFF, M.L. Da música, seus usos e recursos. São Paulo: Editora UNESP, 2002. 172 p.

SILVA, E.L.; MENEZES. E.M. Metodologia da pesquisa e elaboração de dissertação, UFSC, 4. ed. Ver. Atual:Florianópolis, 2005.

SILVA, G. Após sofrer AVC, aposentado aposta na musicoterapia para se recuperar: tratamento está entre alternativas oferecidas pelo SUS. 2017. Disponível em: <http://www.jornalnh.com.br/_conteudo/2017/04/vida/viver_com_saude/2098309-apossofrer-avc-aposentado-aposta-na-musicoterapia-para-se-recuperar.html>. Acesso em: 24 maio 2017. 
Id on Line Revista Multidisciplinar e de Psicoloqia

Id on Line Multidisciplinary and Psycology Journal

SOCAL, M. P. Genes Principais e Genes Predisponentes à Doença de Parkinson: ESTUDO SOBRE OS GENES PARK 2, PARK6, PARK7, PARK8, SCA1, SCA2, SCA3, SCA6, SCA7 E O GENE DA GLUCOCEREBROSIDASE. 2008. 121 f. Dissertação (Mestrado) - Curso de Medicina, Programa de Pós-graduação em Medicina: Ciências Médicas, Universidade Federal do Rio Grande do Sul, Porto Alegre, 2008. Cap. 1.

SOUZA, L. M.; LAUTERT, L.; HILLESHEIN, E. F. Qualidade de vida e trabalho voluntário em idosos. Rev. esc. enferm. USP, São Paulo, v. 45, n. 3, p. 665-671, 2011.

SOUZA, R.G.; BORGES, V.; SILVA, S.M.C.A.; FERRAZ, H.B. Quality of life scale in Parkinson's disease: PDQ-39 (Brazilian Portuguese version) to assess patients with and without levodopa motor fluctuation. Arq Neuropsiquiatr., São Paulo, v. 65, n. 3, p. 789-791, 2007.

VALLEJO, M. P. La musicoterapia. Fundación Borja Sanchez. Innovación y experiencias educativas, Castelló - Espanha, n. 33, p. 1-11, 2010

VIVA BEM COM PARKINSON. SINTOMAS. 2015. Disponível em: <http://vivabemcomparkinson.com.br/sintomas/>. Acesso em: 28 abr. 2017.

Como citar este artigo (Formato ABNT):

SANTOS, Fabrina R.; CORONAGO, Virgínia M.M.O. Uso da Musicoterapia como Terapia Alternativa no Tratamento da Doença de Parkinson. Id on Line Revista Multidisciplinar e de Psicologia, Maio de 2017, vol.11, n.35, p. 341-360. ISSN: 1981-1179.

Recebido: 25.05 .2017

Aceito: 26.05 .2017 